\title{
Thyroid Cancer Patients' View of Clinician Professionalism and Multidisciplinary Approach to Their Management
}

\author{
Juan J Díez $\mathbb{D}^{1-4}$ \\ Juan C Galofré (D) ${ }^{4-6}$ \\ 'Department of Endocrinology, Hospital \\ Universitario Puerta de Hierro \\ Majadahonda, Madrid, Spain; ${ }^{2}$ Instituto de \\ Investigación Sanitaria Puerta de Hierro \\ Segovia de Arana (IDIPHISA), Madrid, \\ Spain; ${ }^{3}$ Department of Medicine, \\ Universidad Autónoma de Madrid, \\ Madrid, Spain; ${ }^{4}$ Thyroid Task Force from \\ the Sociedad Española de Endocrinología \\ y Nutrición (SEEN), Madrid, Spain; \\ ${ }^{5}$ Department of Endocrinology, Clínica \\ Universidad de Navarra, Pamplona, Spain; \\ ${ }^{6}$ Instituto de Investigación Sanitaria de \\ Navarra (IdiSNA), Pamplona, Spain
}

Correspondence: Juan J Díez Department of Endocrinology, Hospital Universitario Puerta de Hierro Majadahonda, Calle Manuel de Falla, I, Majadahonda, Madrid, 28222, Spain

Tel +349II917230

Email juanjose.diez@salud.madrid.org
Objective: The objective of this study was to query thyroid cancer patients about 1) both the characteristics of the healthcare facilities where they were treated and the healthcare professionals that provided that treatment, as well as 2) the multidisciplinary approach used in the treatment process.

Methods: Using a web-based survey, patients were asked to give their opinion of the healthcare centers, the professionalism of their team of specialists, and the thyroid cancer multidisciplinary teams (MDT).

Results: For the 485 patients that responded, the most highly rated aspect of healthcare centers was the reduced waiting time between diagnosis and surgical intervention, an opinion expressed by $62.7 \%$ of patients. The most appreciated aspect of professionalism was the kindness shown toward patients by healthcare staff $(66.6 \%)$. About $44.3 \%$ of patients were aware of the existence of thyroid cancer MDT. Most of respondents (82.7\%) agreed that patients' opinions should be considered by their physicians when making treatment decisions.

Conclusion: We conclude that most patients with thyroid cancer appreciate therapeutic efficacy and kindness, and almost all are clearly in favor of using a multidisciplinary approach to their disease. Since such patients often demand to participate in the decisionmaking process, multidisciplinary teams should make every effort to share information with, and to integrate the opinion of, patients in the management of their thyroid disease.

Keywords: thyroid cancer, professionalism, multidisciplinary approach, survey, patient opinion

\section{Introduction}

The American Board of Internal Medicine has established the fundamental principle of primacy of patient welfare. ${ }^{1}$ This principle insists that the interests of patients be placed above those of the physician. The cornerstone of the patient-doctor relationship is medical professionalism. ${ }^{1}$ Empathy and altruism are two fundamental characteristics of that professionalism, though they change over time and help to maintain the trust that patients have in their physicians. Both empathy and altruism have a positive impact on patients. ${ }^{2}$

Multidisciplinary teams (MDT) in cancer have evolved as a key tool in helping to improve professionalism, and the use of MDTs in the management of thyroid cancer is universally accepted. ${ }^{3,4}$ Specifically, the importance of MDTs in the management of thyroid cancer patients has been widely praised, with some studies showing that MDTs are associated with a range of benefits including better clinical 
outcomes. $^{2,5-8}$ Nevertheless, and perhaps surprisingly, little research has been carried out as to the opinion of thyroid cancer patients on physicians' professionalism or MDTs nor on the impact of MDTs on the opinion of patients of health care received. Some data have shown that failure by healthcare professionals to consider a patient's opinion can lead to inadequate medical advice. ${ }^{9}$ In response, it is now recommended that healthcare professionals evaluate the impact of MTDs on patient satisfaction and quality of life. ${ }^{10}$ While few instruments may be available to measure the impact of professionalism, ${ }^{11}$ per se, it might nevertheless be of interest to gauge the impact of MDTs and professionalism on patients and treatment outcomes. This approach can be reached analysing the patient point of view.

Therefore, the aim of this study was to explore how thyroid cancer patients evaluate the professionalism of their healthcare service providers and how patients view the role of the MDTs involved in their care in order to identify areas in need of improvement.

\section{Methods}

\section{Design of the Study and Responding Patients}

The study design, characteristics of the survey and the sample of interviewed patients have been previously reported in detail. ${ }^{12}$ In brief, our study is a nationwide survey of patients with thyroid cancer of any type, disseminated through the website of the Asociación Española de Cáncer de Tiroides (Spanish Association of Thyroid Cancer, AECAT). The survey was distributed after obtaining the approval of the Board of Directors of AECAT. It was approved by the Clinical Research Ethics Committees of the Hospital Universitario Puerta de Hierro Majadahonda (Madrid) and the Clínica Universidad de Navarra (Pamplona). Written informed consent was waived by our institutional review boards because this study consisted of conducting a voluntary web-based survey. To maintain anonymity, patients were not asked their address, city, telephone number or any other personal data.

The studied sample consisted of 485 patients $(88.5 \%$ females), aged $43.4 \pm 9.9$ years (mean $\pm \mathrm{SD}$ ), with a median (interquartile range) time of evolution of thyroid cancer of 4 (2-7) years. Almost half of the responding patients (49.7\%) had a university education level. Most patients (78.8\%) had papillary thyroid cancer. Other histological types were: follicular, $8.2 \%$; medullary, $5.6 \%$; other, $3.7 \%$; and unknown $3.7 \% .80 .8 \%$ of the patients had been treated with one or more doses of postoperative radioiodine. Disease status of patients at the time of the survey was as follows: cured, $52.0 \%$; not cured, but without need for therapy (ie, presence of biochemical or structural data suggesting persistence of disease that only requires monitoring), 36.1\%, and not cured with need for therapy, $12.0 \%$. At least one chronic complication from the disease or its treatment, including hypoparathyroidism, dry mouth, local discomfort, dysphonia, neck mobility problems and dysgeusia, was reported by 383 patients $(79.0 \%)$.

\section{Inquired Opinions and Assessments}

In the questionnaire, we first asked patients their opinion of the healthcare facilities where they were usually treated and received follow-up care for their disease (Supplementary Material). A 5-point scale was used to assess the importance that the patients assigned to each of the six items asked, with 1 being the least important and 5 being the most. The same scale was used to assess 10 aspects of professionalism of the healthcare specialists who usually treated them or provided follow-up care for their thyroid cancer.

Second, we enquired as to patients' knowledge of their thyroid cancer MDT. Specifically, they were asked if they knew what a MDT was, if they knew whether their hospital had one, and if they knew whether their case had been evaluated by an MDT.

Third, we asked the patients for their opinion of five statements regarding the clinical approach followed with thyroid cancer patients.

\section{Statistical Analysis}

Categorical variables are presented in text, tables and figures as absolute values, ratios, or percentages. For ratio comparisons, the chi-square test or Fisher's exact test was used. Multivariate logistic regression analysis was used to assess the influence of putative predictive factors influencing patient agreement with the following statements related to the multidisciplinary approach to thyroid cancer: "Thyroid cancer is complex and requires the intervention of several specialists", "Specialists must make decisions together with other hospital specialists", and "Patient's opinion should be taken into account by doctors when making treatment decisions". Two-tailed tests were used, and differences were considered significant when $\mathrm{P}<0.05$. 


\section{Results}

\section{Patient Opinion of Health Centers and Professionals}

The opinions held by patients of the clinics they visited during thyroid cancer treatment follow-up appears in Figure 1A. The aspects considered most important by patients were: a reduced waiting time between diagnosis and surgical intervention ( $62.7 \%$ of the patients), the ease of making appointments for blood and imaging tests $(58.6 \%)$, and the cleanliness and comfort of the waiting room $(57.7 \%)$.

Figure 1B shows the importance given to the professionalism of healthcare staff during thyroid cancer treatment. Gestures of kindness and compassion toward patients during the visits were considered most important by 323 patients $(66.6 \%)$, followed by the ability of staff to give understandable treatment information (64.3\%), scientific information about their thyroid cancer (61.5\%), and the ability of staff to liaise with other specialists in the hospital (60.4\%).

\section{Awareness of Multidisciplinary Teams}

Two hundred fifteen patients (44.3\%) responded affirmatively to the question of whether they had heard of thyroid cancer MDTs. One hundred eighty-five (38.1\%) knew that there was a MDT at their hospital and, of these, 169 (34.8\%) stated that their case had been evaluated by one.

Table 1 breaks down patients responding affirmatively to the question of whether they had heard of MDTs before by gender, age, level of education, pathology subtype (papillary or non- papillary), tumor extension at diagnosis, treatment with radioiodine, disease status and complications.

We found no differences among those patients in terms of gender, age, education, or tumor type. However, patients diagnosed with more severe disease, that is, those whose cancer had extended to lymph nodes or involving distant metastases, had a significantly higher percentage of affirmative answers regarding MDTs than those with disease limited solely to the thyroid. Similarly, patients who had not received radioiodine and those who were not cured showed a significantly higher percentage of affirmative answers to the three questions regarding MDTs than both those who had received radioiodine and those who were cured.

\section{Patients' Opinion About the Clinical Approach to Thyroid Cancer}

Figure 2 shows the level of agreement or disagreement with 5 statements about the clinical approach to patients with thyroid cancer. Most patients agree that thyroid cancer is complex and requires the intervention of several specialists $(89.3 \%)$, that specialists must make decisions together with other hospital specialists $(89.7 \%)$, and that the patient's opinion should be considered by doctors when deciding treatment $(82.7 \%)$.

\section{Factors Influencing Patient Opinion}

We studied the influence of several variables regarding the issues raised by the multidisciplinary approach. As summarized in Table 2, neither gender, age, level of education, pathology subtype, tumor extension, receipt of radioiodine, disease status nor the presence of complications influenced patient opinion. Agreement with the statement "Thyroid cancer is complex and requires the intervention of several specialists" was associated with a patient's knowledge of the existence of MDTs and with the evaluation of a patient's case by an MDT. Agreement with the statement "Specialists must make decisions together with other hospital specialists" was greater among patients who had known of the existence of MDTs, had had an MDT at their hospital, and whose case had been evaluated by one. However, we found no relationship between whether or not a patient agreed with the statement "Patient's opinion should be taken into account by doctors when making treatment decisions" and the previously mentioned variables.

Several models of logistic regression analysis were performed to evaluate the influence of the variables listed in Table 2 on whether or not the patients agreed with the three statements. Patients who knew of the existence of MDTs agreed much more with the statements "Thyroid cancer is complex and requires the intervention of several specialists" (OR 2.12, 95\% CI, 1.13-3.97; $\mathrm{P}=0.020$ ) and "Specialists must make decisions together with other hospital specialists" (OR 3.13, 95\% CI, 1.56-6.27; P=0.001). The knowledge that there was an MDT in the patient's hospital or that his or her own case had been evaluated by an MDT did not significantly influence the remainder of the patient's opinions in this multivariate regression model. 


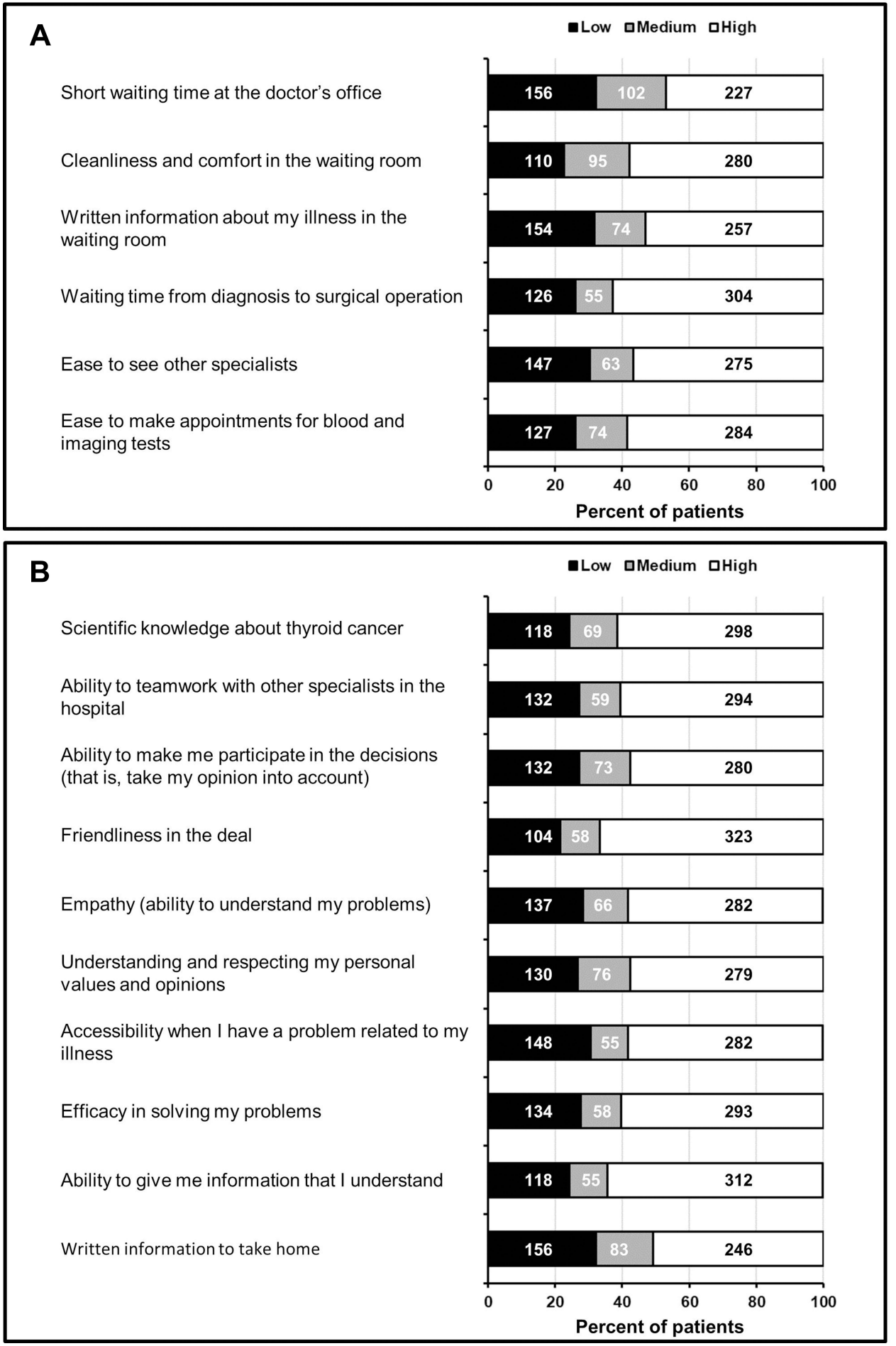

Figure I Assessment of the importance of several items related to the clinic where patients are usually seen in the follow-up of their disease (A), and the characteristics of professionalism of specialists involved in the follow up of their thyroid cancer (B). Responses were measured on a 5-point scale and classified according to low (I-2), medium (3) and high (4-5) importance. Abscissa scale: percentage of patients. Values inside the rectangles indicate the number of patients in each group.

\section{Discussion}

In recent years, numerous factors have changed the way doctors deal with patients and vice versa. Patients today are generally more demanding and better informed than in the past. Factors such as increased access to medical information via the Internet, increased patient selfconfidence, and a more educated public, among others, have dramatically affected how medicine is currently 
Table I Patient Knowledge About the Existence of Multidisciplinary Teams on Thyroid Cancer and the Assessment of Their Case in the Hospital

\begin{tabular}{|c|c|c|c|c|}
\hline & & $\begin{array}{l}\text { I Know the Existence of } \\
\text { MDTs on Thyroid Cancer }\end{array}$ & $\begin{array}{l}\text { In My Hospital There is } \\
\text { a MDT on Thyroid Cancer }\end{array}$ & $\begin{array}{l}\text { My Case Has Been } \\
\text { Evaluated by a MDT }\end{array}$ \\
\hline & & No. Patients (\%) & No. Patients (\%) & No. Patients (\%) \\
\hline All & & $215(44.3)$ & $185(38.1)$ & $169(34.8)$ \\
\hline Gender & $\begin{array}{l}\text { Female } \\
\text { Male }\end{array}$ & $\begin{array}{l}182(42.4) \\
33(58.9)^{*}\end{array}$ & $\begin{array}{l}157(36.6) \\
28(50.0)\end{array}$ & $\begin{array}{l}143(33.3) \\
26(46.4)\end{array}$ \\
\hline Age & $\begin{array}{l}\leq 43 \mathrm{yr} \\
>43 \mathrm{yr}\end{array}$ & $\begin{array}{l}105(42.2) \\
110(46.6)\end{array}$ & $\begin{array}{l}92(36.9) \\
93(39.4)\end{array}$ & $\begin{array}{l}85(34.1) \\
84(35.6)\end{array}$ \\
\hline Education & $\begin{array}{l}\text { Primary or secondary } \\
\text { University }\end{array}$ & $\begin{array}{l}99(40.6) \\
116(48.1)\end{array}$ & $\begin{array}{l}93(38.1) \\
92(38.2)\end{array}$ & $\begin{array}{l}83(34.0) \\
86(35.7)\end{array}$ \\
\hline Tumor type & $\begin{array}{l}\text { Papillary } \\
\text { Non-papillary }\end{array}$ & $\begin{array}{l}170(44.5) \\
45(43.4)\end{array}$ & $\begin{array}{l}142(37.2) \\
43(4 \mid .7)\end{array}$ & $\begin{array}{l}I 28(33.5) \\
4 \mid(39.8)\end{array}$ \\
\hline $\begin{array}{l}\text { Tumor extension } \\
\text { at diagnosis }{ }^{\dagger}\end{array}$ & $\begin{array}{l}\text { Thyroid } \\
\text { LN or distant } \\
\text { metastases }\end{array}$ & $\begin{array}{l}100(40.5) \\
114(49.8)^{*}\end{array}$ & $\begin{array}{c}81(32.8) \\
103(45.0)^{* *}\end{array}$ & $\begin{array}{c}71(28.7) \\
98(42.8)^{* *}\end{array}$ \\
\hline $\begin{array}{l}\text { Receipt of } \\
\text { radioiodine }^{t \dagger}\end{array}$ & $\begin{array}{l}\text { No } \\
\text { Yes }\end{array}$ & $\begin{array}{l}5 \mid(56.0) \\
\mid 63(4 \mid .6)^{*}\end{array}$ & $\begin{array}{c}48(52.7) \\
136(34.7)^{* * *}\end{array}$ & $\begin{array}{c}44(48.4) \\
124(3 \mid .6)^{* * *}\end{array}$ \\
\hline Disease status & $\begin{array}{l}\text { Cured } \\
\text { Not cured }\end{array}$ & $\begin{array}{l}179(41.9) \\
36(62.1)^{* *}\end{array}$ & $\begin{array}{c}149(34.9) \\
36(62.1)^{* * *}\end{array}$ & $\begin{array}{c}136(31.9) \\
33(56.9)^{* * *}\end{array}$ \\
\hline Complications & $\begin{array}{l}\text { No } \\
\text { Yes }\end{array}$ & $\begin{array}{l}48(47.1) \\
167(43.6)\end{array}$ & $\begin{array}{l}42(4 \mid .2) \\
143(37.3)\end{array}$ & $\begin{array}{c}35(34.3) \\
134(35.0)\end{array}$ \\
\hline
\end{tabular}

Notes: Statistically significant values are indicated in bold: $* \mathrm{P}<0.05 ; * * \mathrm{P}<0.01$; $* * \mathrm{P}<0.001 .{ }^{\dagger}$ Respondents: $\mathrm{n}=476$ (thyroid, 247 ; lymph nodes or distant metastases, 229 ). ${ }^{\dagger+}$ Respondents: n=483 (no, 91; yes, 392).

Abbreviations: MDT, multidisciplinary team; LN, lymph node.

being practised in many parts of the world. In addition, thyroid cancer is a disease frequently diagnosed in young middle-aged subjects. These younger patients are more likely to seek out the latest information online and insist on playing a prominent role in their own care. They embrace multidisciplinary care and groupthink. ${ }^{13}$ Hence, undeniably, today's patients are expecting, if not demanding, to be actively involved in their treatment. This sentiment has been succinctly encapsulated by the British National Health System Department of Health in the phrase "No decision about me, without me". 9

Notwithstanding its originality, this participative approach has turned out to be extremely beneficial to all concerned. The novel elements have had a positive impact on the management of patients and their clinical outcomes. ${ }^{9,14,15}$ This involves maintaining a heightened level of communication between patient and doctor. Some information suggests that clinicians (possibly misguided by personal interests, including economic or research-related ones) may be poor at judging a patient's treatment preference. ${ }^{16}$ Previous reports have highlighted that one of the key barriers to effective decision making in MDT meetings has been a failure to adequately consider patient-centred information. ${ }^{17}$ Misunderstandings may be commonplace. For instance, at times, what clinicians perceive as an agreement, patients may perceive as simply being informed. ${ }^{18}$ In any event, an important benefit of the patient-involved approach is greater compliance with therapy, with positive health consequences. ${ }^{9,14}$

Our survey has found that thyroid cancer patients today demand to participate in the decision-making process and support a multidisciplinary approach in the management of their disease. This would certainly make it easier to determine whether a patient should form part of an MDT. However, a survey of over 2000 cancer health professionals in the UK revealed that the majority felt it was 
A single specialist (my usual doctor) is the one who should indicate the treatment at all times

Thyroid cancer is complex and requires the intervention of several specialists

Each specialist can make decisions according to their criteria without being coordinated

Specialists must make decisions together with other hospital specialists

Patient's opinión should be taken into account by doctors when making treatment decisions
-Agree םNeutral aDisagree

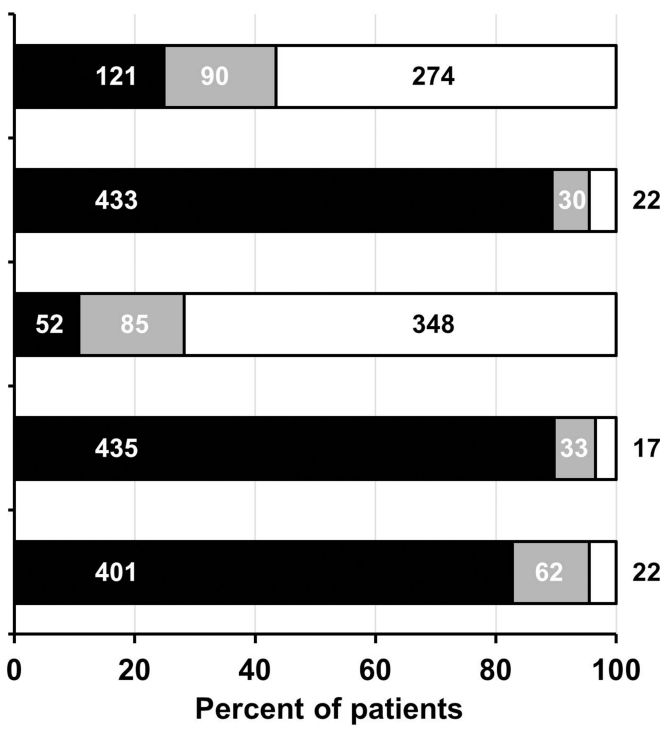

Figure 2 Degree of agreement with five statements regarding the clinical approach of patients with thyroid cancer. Patients provided their perceptions by classifying them into three groups: agree, neutral, disagree. Abscissa scale: percentage of patients. Values inside the rectangles indicate the number of patients in each group.

neither desirable nor practical to include patients in MDT meetings. ${ }^{19}$ Certainly, a discussion of a patients' disease with them present could result in unnecessary anxiety in the patient although some data suggest that this is not necessarily the case. ${ }^{20}$ Others might argue that the presence of the patient at an MDT meeting could discourage free and open discussion among the healthcare professionals. ${ }^{3}$ While the jury may still be out, the authors feel that thyroid cancer patient participation on MDTs makes good sense. Transparency is rarely a bad thing. The sharing of information between patient and clinician is an indicator of good practice. ${ }^{9,21}$ Therefore, the MDT (or its representative) should discuss all possible treatment options with the patient after the meeting. ${ }^{3}$ Caregivers must guarantee that patients are fully informed both before and after any diagnostic or treatment procedure. Where such information is not integral to decision making in MDT meetings, there is a risk of poor-quality clinical decisions. Such decisions may result unacceptable to the patient, which may lead to the need for re-discussion by the MDT and, consequently, an unnecessary delay in treatment. ${ }^{22-25}$

There are many current aspects of oncology and, more specifically in thyroid cancer management, not supported by evidence. Critical decisions such as the extent of thyroid surgery or the need for radioiodine ablative treatment, its preparation and dose are questions subject of much debate. $^{26-29}$ All treatment decisions are preference- sensitive and require shared decision-making, notably when benefits are limited or uncertain and may cause harm to or diminish quality of life. ${ }^{30}$ Patients must be empowered to decide on the course of their own therapy. ${ }^{19}$

Although patients surveyed may have had limited knowledge of MDTs or limited opportunity to participate in MDT meetings, they nevertheless generally support their involvement in MDT meetings regarding treatment. Those patients who were aware of the MDT meetings reported feeling more confident. ${ }^{3}$ Advances in our knowledge of thyroid cancer have led to increased complexity in both the diagnosis and treatment and thus reinforce the need for a multidisciplinary approach to thyroid cancer management. We need to ensure MDT processes are both efficient and patient-centred. ${ }^{9}$

The main contributions of our survey are well summarised in Figures 1 and 2. As expected, the patient's chief concern is the time between diagnosis and surgical intervention. The British guidelines recommend a maximum of a month from "decision to treat" to first definitive treatment. ${ }^{4}$ This is an achievable, albeit challenging, goal for any overworked and understaffed national health system. On the other hand, the survey provides an opportunity to enumerate the goals health care staff should work toward in order to improve their level of professionalism (Figure 2). The ideal doctor is the one who is kind and approachable and shares information with the patient. Patients know that thyroid cancer management is complex 
Table 2 Proportion of Patients Who Agree with the Three Statements That Reached the Highest Degree of Agreement Classified According to Different Variables

\begin{tabular}{|c|c|c|c|c|}
\hline & & $\begin{array}{l}\text { Thyroid Cancer is } \\
\text { Complex and } \\
\text { Requires the } \\
\text { Intervention of } \\
\text { Several Specialists }\end{array}$ & $\begin{array}{l}\text { Specialists Must } \\
\text { Make Decisions } \\
\text { Together with } \\
\text { Other Hospital } \\
\text { Specialists }\end{array}$ & $\begin{array}{c}\text { Patient's Opinion } \\
\text { Should Be Taken into } \\
\text { Account by Doctors } \\
\text { When Making } \\
\text { Treatment Decisions }\end{array}$ \\
\hline & & No. Patients (\%) & No. Patients (\%) & No. Patients (\%) \\
\hline \multirow[t]{2}{*}{ Gender } & Female & $381(88.8)$ & $383(89.3)$ & $35 I(8 I .8)$ \\
\hline & Male & $52(92.9)$ & $52(92.9)$ & $50(89.3)$ \\
\hline \multirow[t]{2}{*}{ Age } & $\leq 43 \mathrm{yr}$ & $224(90.0)$ & $224(90.0)$ & $204(81.9)$ \\
\hline & $>43 \mathrm{yr}$ & $209(88.6)$ & $211(89.4)$ & $197(83.5)$ \\
\hline \multirow[t]{2}{*}{ Education } & Primary and secondary & $218(89.3)$ & $217(88.9)$ & $206(84.4)$ \\
\hline & University & $215(89.2)$ & $218(90.5)$ & $195(80.9)$ \\
\hline \multirow[t]{2}{*}{ Tumor type } & Papillary & $34 \mid(89.3)$ & $340(89.0)$ & $311(8 I .4)$ \\
\hline & Non-papillary & $92(89.3)$ & $95(92.2)$ & $90(87.4)$ \\
\hline \multirow[t]{2}{*}{ Tumor extension at diagnosis $^{\dagger}$} & Thyroid & $218(88.3)$ & $218(88.3)$ & $207(83.8)$ \\
\hline & LN or distant metastases & $207(90.4)$ & $208(90.8)$ & $185(80.8)$ \\
\hline \multirow[t]{2}{*}{ Receipt of radioiodine $\mathrm{t}^{\dagger \dagger}$} & No & $81(89.0)$ & $82(90.1)$ & $80(87.9)$ \\
\hline & Yes & $350(89.3)$ & $35 \mathrm{I}(89.5)$ & $320(81.6)$ \\
\hline \multirow[t]{2}{*}{ Disease status } & Cured & $378(88.5)$ & $382(89.5)$ & $352(82.4)$ \\
\hline & Not cured & $55(94.8)$ & $53(91.4)$ & $49(84.5)$ \\
\hline \multirow[t]{2}{*}{ Complications } & No & $89(87.3)$ & $89(87.3)$ & $83(81.4)$ \\
\hline & Yes & $344(89.8)$ & $346(90.3)$ & $318(83.0)$ \\
\hline \multirow[t]{2}{*}{ I know the existence of MDTs } & No & $233(86.3)$ & $23 I(85.6)$ & $224(83.0)$ \\
\hline & Yes & $200(93.0)^{*}$ & $204(94.9)^{* * *}$ & $177(82.7)$ \\
\hline \multirow[t]{2}{*}{ In my hospital there is a MDT } & No & $262(87.3)$ & $216(87.0)$ & $25 \mathrm{I}(83.7)$ \\
\hline & Yes & I7| (92.4) & $174(94.1)^{* * *}$ & $150(8 \mid .1)$ \\
\hline \multirow[t]{2}{*}{ My case has been evaluated by a MDT } & No & $276(87.4)$ & 274 (86.7) & $263(83.2)$ \\
\hline & Yes & I $57(92.9)^{*}$ & $161(95.3)^{* * *}$ & I38 (8I.7) \\
\hline
\end{tabular}

Notes: Statistically significant values are indicated in bold: $* \mathrm{P}<0.05 ; * * \mathrm{P}<0.01 .{ }^{\dagger}$ Respondents: $\mathrm{n}=476$ (thyroid, 247 ; lymph nodes or distant metastases, 229 ). ${ }^{\dagger \dagger}$ Respondents: $\mathrm{n}=483$ (no, 91; yes, 392).

Abbreviations: MDT, multidisciplinary team; LN, lymph node.

and requires the contribution of a many experts. Interestingly, our data also suggest that treatment outcome is related to the patient awareness of the MDTs, since patients who did not reach cure showed a significantly higher percentage of affirmative answers to the three statements (Table 1). However, treatment outcome does not seem to influence the opinion of the patients as to the functioning of these teams, since, as seen in Table 2, the level of agreement to the three statements were similar in both cured and not cured patients. These results suggest that thyroid cancer patients perceive and appreciate teamwork and a multidisciplinary approach, regardless of their own treatment outcome. These results support the important role of the MDT in thyroid cancer treatment.

As in all surveys, study limitations are, first and foremost, related to the potential bias of the responders. AECAT members have a greater awareness of their disease and, thus, are likely to be more interested in the topic than the average thyroid cancer patient in Spain. For the same reason, our conclusions may also be more country-specific and, therefore, not fully extrapolatable to other countries. Also, the results are based on surveys submitted by participating patients without independent verification. The present study focuses on the analysis of the opinion of patients about the 
professionalism of their doctors at a specific moment. Certainly, patients' view can change over time. Therefore, in the future, it would be interesting to study how opinion can change and the factors that drive these changes. To ensure that results are reported as fully and accurately as possible we followed the STROBE guidelines (https://www. strobe-statement.org/index.php?id=strobe-home).

The results of this survey may have a practical impact on the treatment of thyroid cancer patients by healthcare providers. Patients value the professionalism of their physicians. Nevertheless, they believe that their opinion should not only be respected but also considered in the decision-making processes governing the diagnostic and therapeutic procedures that directly affect them. Patients now insist on their active participation in multidisciplinary teams and so clinicians and health officials must make every effort to convert these demands into reality.

In conclusion, our work indicates that thyroid cancer patients support a multidisciplinary approach in the management of their disease and demand to participate in the team decision-making process. Multidisciplinary teams work well for both patient and healthcare personnel alike. Transparency, as provided by patient participation in MDTs, leads to enhanced trust and enhanced trust, in turn, leads to improved treatment outcomes. A win-win situation for everyone.

\section{Acknowledgments}

The authors gratefully acknowledge the efforts of AECAT staff members in the dissemination of this survey, especially Arantxa Sáez and Verónica Villa, and all the patients who took the time to complete the survey.

\section{Author Contributions}

All authors contributed to data analysis, drafting or revising the article, have agreed on the journal to which the article will be submitted, gave final approval of the version to be published, and agree to be accountable for all aspects of the work.

\section{Disclosure}

The authors declare that they have no conflicts of interest in relation to this work.

\section{References}

1. ABIM Foundation. American Board of Internal Medicine; ACP-ASIM Foundation. American College of Physicians-American Society of Internal Medicine; European Federation of Internal Medicine. Medical professionalism in the new millennium: a physician charter. Ann Intern Med. 2002;136:243-246. doi:10.7326/0003-4819-1363-200202050-00012
2. Hojat M, Louis DZ, Markham FW, Wender R, Rabinowitz C, Gonnella JS. Physicians' empathy and clinical outcomes for diabetic patients. Acad Med. 2011;86:359-364. doi:10.1097/ACM.0b013e3182086fe1

3. Raine R, Wallace I, Nic a'Bháird C, et al. Improving the effectiveness of multidisciplinary team meetings for patients with chronic diseases: a prospective observational study. Health Serv Delivery Res. 2014;2 (37):1-72. PMID: 25642498. doi:10.3310/hsdr02370

4. Perros P, Boelaert K, Colley S, et al.; British Thyroid Association. Guidelines for the management of thyroid cancer. Clin Endocrinol (Oxf). 2014;81(Suppl 1):1-122.

5. Díez JJ, Galofré JC, Oleaga A, Grande E, Mitjavila M, Moreno P; Grupo de Trabajo de Cáncer de Tiroides de la Sociedad Española de Endocrinología y Nutrición. Consensus statement for accreditation of multidisciplinary thyroid cancer units. Endocrinol Nutr. 2016;63:e115. doi:10.1016/j.endonu.2015.07.005

6. Díez JJ, Galofré JC, Oleaga A, Grande E, Mitjavila M, Moreno P. Characteristics of professionalism of specialists and advantages of multidisciplinary teams in thyroid cancer: results of a national opinion survey. Endocrinol Diabetes Nutr. 2019;66:74-82. doi:10.1016/ j.endinu.2018.10.009

7. Kesson EM, Allardice GM, George WD, Burns HJG, Morrison DS. Effects of multidisciplinary team working on breast cancer survival: retrospective, comparative, interventional cohort study of 13722 women. Br Med J. 2012;344:e2718. doi:10.1136/bmj.e2718

8. Hong NJL, Wright FC, Gagliardi AR, Paszat LF. Examining the potential relationship between multidisciplinary cancer care and patient survival: an international literature review. J Surg Oncol. 2010;102:125-134. doi:10.1002/jso.21589

9. Taylor C, Finnegan-John J, Green JS. "No decision about me without me" in the context of cancer multidisciplinary team meetings: a qualitative interview study. BMC Health Serv Res. 2014;14:488. doi:10.1186/s12913-014-0488-2

10. Pillay B, Wootten AC, Crowe H, et al. The impact of multidisciplinary team meetings on patient assessment, management and outcomes in oncology settings: a systematic review of the literature. Cancer Treat Rev. 2016;42:56-72. doi:10.1016/j.ctrv.2015.11.007

11. Veloski JJ, Fields SK, Boex JR, Blank LL. Measuring professionalism: a review of studies with instruments reported in the literature between 1982 and 2002. Acad Med. 2005;80:366-370. doi:10.1097/ 00001888-200504000-00014

12. Díez JJ, Galofré JC. Thyroid cancer patients satisfaction at the management outcome: an analysis of the results of a nationwide survey in 485 subjects. BMC Health Serv Res. 2021;21:158. doi:10.1186/s12913-021-06158-0

13. Waljee JF, Chopra V, Saint S. Mentoring millennials. JAMA. 2020;323:1716-1717. doi:10.1001/jama.2020.3085

14. Coulter A, Collins A. Making Shared Decision-Making a Reality: No Decision About Me Without Me. London: The Kings Fund; 2011.

15. O'Connor AM, Bennett CL, Stacey D, et al. Decision aids for people facing health treatment or screening decisions. Cochrane Database Syst Rev. 2009;8(3):CD001431.

16. Mulley A, Trimble C, Elwyn G. Patients' Preferences Matter, Stop the Silent Misdiagnosis. London: The Kings Fund; 2012.

17. Lamb BW, Brown KF, Nagpal K, Vincent C, Green JSA, Sevdalis N. Quality of care management decisions by multidisciplinary cancer teams: a systematic review. Ann Surg Oncol. 2011;18:2116-2125. doi:10.1245/s10434-011-1675-6

18. Pieterse AH, Baas-Thijssen MCM, Marjnen CAM, Stiggelbout AM. Clinician and cancer patient views on patient participation in treatment decision-making: a quantitative and qualitative exploration. $\mathrm{Br}$ J Cancer. 2008;99:875-882. doi:10.1038/sj.bjc.6604611

19. Taylor C, Ramirez AJ. Multidisciplinary team members' views about MDT working: results from a survey commissioned by the National Cancer Action Team. National Cancer Action Team; 2009. Available from: http://www.ncin.org.uk/view.aspx?rid=137. Accessed April 30, 2021. 
20. Chaillou D, Mortuaire G, Deken-Delannoy V, Rysman B, Chevalier D, Mouawad F. Presence in head and neck cancer multidisciplinary team meeting: the patient's experience and satisfaction. Eur Ann Otorhinolaryngol Head Neck Dis. 2019;136:75-82. doi:10.1016/j.anorl.2018.10.003

21. Rabi DM, Kunneman M, Montori VM. When guidelines recommend shared decision-making. JAMA. 2020;323:1345-1346. doi:10.1001/ jama.2020.1525

22. Blazeby JM, Wilson L, Metcalfe C, Nicklin J, English R, Donovan JL. Analysis of clinical decision-making in multi-disciplinary cancer teams. Ann Oncol. 2006;17:457-460. doi:10.1093/annonc/mdj102

23. Wood JJ, Metcalfe C, Paes A, et al. An evaluation of treatment decisions at a colorectal cancer multi-disciplinary team. Colorectal Dis. 2008;8:769-772. doi:10.1111/j.1463-1318.2007.01464.x

24. Kidger J, Murdoch J, Donovan JL, Blazeby JM. Clinical decision-making in a multidisciplinary gynaecological cancer team: a qualitative study. BJOG. 2009;116:511-517. doi:10.1111/j.14710528.2008.02066.x

25. Lanceley A, Savage J, Menon U, Jacobs I. Influences on multidisciplinary team decision-making. Int $J$ Gynecol Cancer. 2008;18:215-222. doi:10.1111/j.1525-1438.2007.00991.x
26. Molinaro E, Campopiano MC, Pieruzzi L, et al. Active surveillance in papillary thyroid microcarcinomas is feasible and safe: experience at a single Italian center. J Clin Endocrinol Metab. 2020;105:dgz113.

27. Anda Apiñániz E, Zafon C, Ruiz Rey I, et al. The extent of surgery for low-risk 1-4 cm papillary thyroid carcinoma: a catch-22 situation. A retrospective analysis of 497 patients based on the 2015 ATA Guidelines recommendation 35. Endocrine. 2020;70:538-543. doi:10.1007/s12020-020-02371-9

28. Lamartina L, Durante C, Filetti S, Cooper DS. Low-risk differentiated thyroid cancer and radioiodine remnant ablation: a systematic review of the literature. $J$ Clin Endocrinol Metab. 2015;100:1748-1761. doi:10.1210/jc.2014-3882

29. Wallner LP, Reyes-Gastelum D, Hamilton AS, Ward KC, Hawley ST, Haymart MR. Patient-perceived lack of choice in receipt of radioactive iodine for treatment of differentiated thyroid cancer. J Clin Oncol. 2019;37:2152-2161. doi:10.1200/JCO.18.02228

30. Gärtner FR, Portielje JE, Langendam M, et al. Role of patient preferences in clinical practice guidelines: a multiple methods study using guidelines from oncology as a case. BMJ Open. 2019;9: e032483. doi:10.1136/bmjopen-2019-032483
Journal of Multidisciplinary Healthcare

\section{Publish your work in this journal}

The Journal of Multidisciplinary Healthcare is an international, peerreviewed open-access journal that aims to represent and publish research in healthcare areas delivered by practitioners of different disciplines. This includes studies and reviews conducted by multidisciplinary teams as well as research which evaluates the results or conduct of such teams or healthcare processes in general. The journal

\section{Dovepress}

covers a very wide range of areas and welcomes submissions from practitioners at all levels, from all over the world. The manuscript management system is completely online and includes a very quick and fair peer-review system. Visit http://www.dovepress.com/testimonials. php to read real quotes from published authors. 